\title{
Right colon angiodysplasia and lower limb chronic obstructive arteropathy: simultaneous endovascular treatment
}

\author{
G Patrizi $^{1 *}$, M Fazi ${ }^{1}$, L Fiengo ${ }^{1}$, G Di Rocco ${ }^{1}$, F Pelle ${ }^{1}$, D Giannotti ${ }^{1}$, L Venturini ${ }^{1}$, F Frezzotti ${ }^{1}$, R Giordano ${ }^{1}$, A Redler ${ }^{1}$, \\ FM Salvatori ${ }^{2}$
}

From XXIII Annual Meeting of the Italian Society of Geriatric Surgery

Lecce, Italy. 2-4 December 2010

\section{Background}

Intestinal angiodyspalsia is a vascular artero-venous malformation of the enteric wall smaller than $1 \mathrm{~cm}$ whose main symptom is enterorrhagy.

Diagnosis is based on colonoscopy and mesenteric selective arteriography. Recently, spiral angio-CT has reached a good diagnostic sensitivity and specificity.

Radical treatment is still surgical resection. Endoscopic approaches are frequently employed even though relapse of hemorrhage and perforation can occur. Super-selective embolization represents another possible therapeutic option, despite the low risk of segmentary intestinal ischemia.

\section{Materials and methods}

We present the case of a 70 year old patient, with a past history of hypertension, myocardial infarction, who came to our attention for a chronic obstructive arteriopathy of the lower extremities and claudicatio at $100 \mathrm{~m}$. The patient also displayed an hypochromic anemia $(\mathrm{Hb}=7 \mathrm{~g} / \mathrm{dL})$; no history of evident bleeding could be demonstrated. Ultrasonography showed the left common iliac artery obstruction and patent femoral, popliteal and tibial arteries.

The patient underwent colonoscopy that revealed a reddish area in the caecum that could be referred to angiodysplasia, and two small peduncolated polyps (0.5 and $0.8 \mathrm{~mm}$ ) that were resected. Histology gave evidence of a low-grade tubular adenoma. Abdominal and lower limbs arteriography confirmed the ultrasonographic

\footnotetext{
* Correspondence: g_patrizi@yahoo.com

'Dipartimento di Scienze Chirurgiche, Policlinico Umberto I, Università di Roma"La Sapienza", Rome, Italy

Full list of author information is available at the end of the article
}

suspicion and we therefore proceeded with primary stenting of the iliac obstruction. At the same time, selective arteriography of the superior mesenteric artery was carried out, showing an angiographic appearance compatible with angiodysplasia of the terminal branches of the ileo-colic artery. Super-selective catheterization and embolization of the vascular malformation with metallic coils was then attempted successfully.

\section{Results}

Endoscopic and angiographic follow-up showed the disappearing of the angiodysplastic area. After 6 and 12 months, no evidence of relapse could be identified at endoscopy. An occult blood test in the stools was negative and complete regression of symptoms was steadily achieved.

\section{Conclusions}

Super-selective embolization is a safe and effective alternative option to surgical resections and endoscopic approach for the treatment of colic angiodysplasia.

\section{Author details \\ 'Dipartimento di Scienze Chirurgiche, Policlinico Umberto I, Università di Roma“La Sapienza", Rome, Italy. 'Dipartimento di Scienze Chirurgiche, Policlinico Umberto I, Università di Roma"La Sapienza", Rome, Italy.}

Published: 24 August 2011

doi:10.1186/1471-2318-11-S1-A42

Cite this article as: Patrizi et al:: Right colon angiodysplasia and lower limb chronic obstructive arteropathy: simultaneous endovascular treatment. BMC Geriatrics 2011 11(Suppl 1):A42.

\section{C)

(C) 2011 Patrizi et al; licensee BioMed Central Ltd. This is an open access article distributed under the terms of the Creative Commons Attribution License (http://creativecommons.org/licenses/by/2.0), which permits unrestricted use, distribution, and reproduction in any medium, provided the original work is properly cited. 